\title{
SOME OF MY MEMORIES OF ARMAND BOREL
}

\author{
BILL CASSELMAN*
}

I first met Armand Borel in 1970 in Princeton at the conference on Prospects in Mathematics. I was talking, I think to Joe Shalika, got excited, and jumped backwards onto his feet. I was horrified, but he merely raised one eyebrow - a neat trick I have wished often that I could perform - and introduced himself. This encounter had no consequence, as far as I can recall, on either of us, except to bring us both to smile occasionally.

Our next meeting was at the Antwerp conference of 1972 on automorphic forms, when we began to discuss the cohomology of arithmetic subgroups of $p$-adic groups. This exchange continued through the spring of 1974, when I visited the Institute at his urging. The two of us conducted a seminar on the representation theory of $p$-adic groups, and continued trying to understand how representation theory played a role in the conjecture of Serre's on the vanishing of certain arithmetic cohomology groups. The final result first appeared in an announcement written by me, but without Armand's prodding and patient encouragement it wouldn't have been finished, and in retrospect I should have acknowledged his help more generously. I probably felt it would have been pretentious to mention it. But other work by both of us came out in other places. Without his encouragement my well-distributed notes on the representation theory of $p$-adic groups would not have been completed, for example. He was perhaps more annoyed than anyone that it didn't eventually get published. What comes out of this story is that his unfailing interest was in mathematics itself, not so much in how exactly credit was distributed. What also comes out is his great interest in working closely with visitors to the Institute. Invariably, as many other visitors can affirm, this interest would include more personal hospitality as well.

We worked on many other projects together, but our best known mutual enterprise, and the one perhaps of longest lasting influence, was organizing the 1977 Corvallis conference. It's hard to imagine now, but at the time we were not encouraged very much to do this; we were told that it was premature and that it was too much work, and there were other objections to the project as well. My own major contribution, to the chagrin of some and the delight of others, was to effect the selection of Corvallis for the conference site. In the process of planning, Armand and I talked to each other by telephone roughly once a week all of 1976/77. By this time we were fairly good friends, but I still remember being extremely nervous the mornings before the calls. Others, too, have commented that on the telephone he was more formidable than in person, often answering in a tone that conveyed distinctly the impression that the last thing in the world he wanted to do was talk on the machine.

Our most extensive mathematical collaboration was on Zucker's conjecture, but in the end we were scooped by others, and the work we did wasn't completed. My own belief is that what we did has more value than is now apparent, but I have to

*Department of Mathematics, University of British Columbia, Vancouver, Canada (cass@math. ubc.ca). 
say that a large and very technical part of it was, as far as I know, written only inside Armand's head, and I doubt that it will be ever reconstructed.

Our collaborations in mathematics became less important in later years than our hiking trips together. As far as I can recall these began in Switzerland, during the period he had a position at ETH. While I was in Zürich we managed to get away nearly every weekend, usually ascending and descending 2,000 meter peaks in a day. For me at my age then, not a serious problem, but for someone Armand's age impressive. It was on one of these trips, passing along a very narrow trail along a ridge that fell steeply away on both sides, that he started to look a bit green and confessed that he suffered all his life from vertigo! It was at the end of this day, I am pretty sure, that I took the photograph of him on the Swiss train, in which he is visibly more relaxed than normally.

I greatly enjoyed visiting Zürich, and about the time when he was trying to decide whether to stay or not Joel Feldman and I decided to tempt him with a long day's walk along the ridge just north of the Eiger, one offering some of the best views on the planet. He was, he told us, overwhelmed, claiming that up until then he had never really known his own country. But it wasn't enough to keep him there, alas.

Among our best trips together were two to the Utah desert, along with Dragan Miličić. The last one took place the summer before he died, during the Park City conference on automorphic forms. One of the pictures accompanying this article shows Dragan and him retreating from the heat in the famous hole-in-the-wall on the road to Echo Park in Dinosaur National Monument, a place in which he found himself extremely happy (hardly complaining at all about the poor meals I cooked).

I miss him both mathematically and personally. At just about the time that he must have first learned that he had only a short time to live, Dragan and I, sitting on a terrace on the Croatian island of Hvar, were telling each other that sometime in the future we should definitely get Armand to come back with us. Above all he loved to swim. I was never quite sure to what extent this was tinged by his pleasure in forcing iron discipline on himself. But nonetheless I am sure he would have loved the isolated beaches of Hvar. 


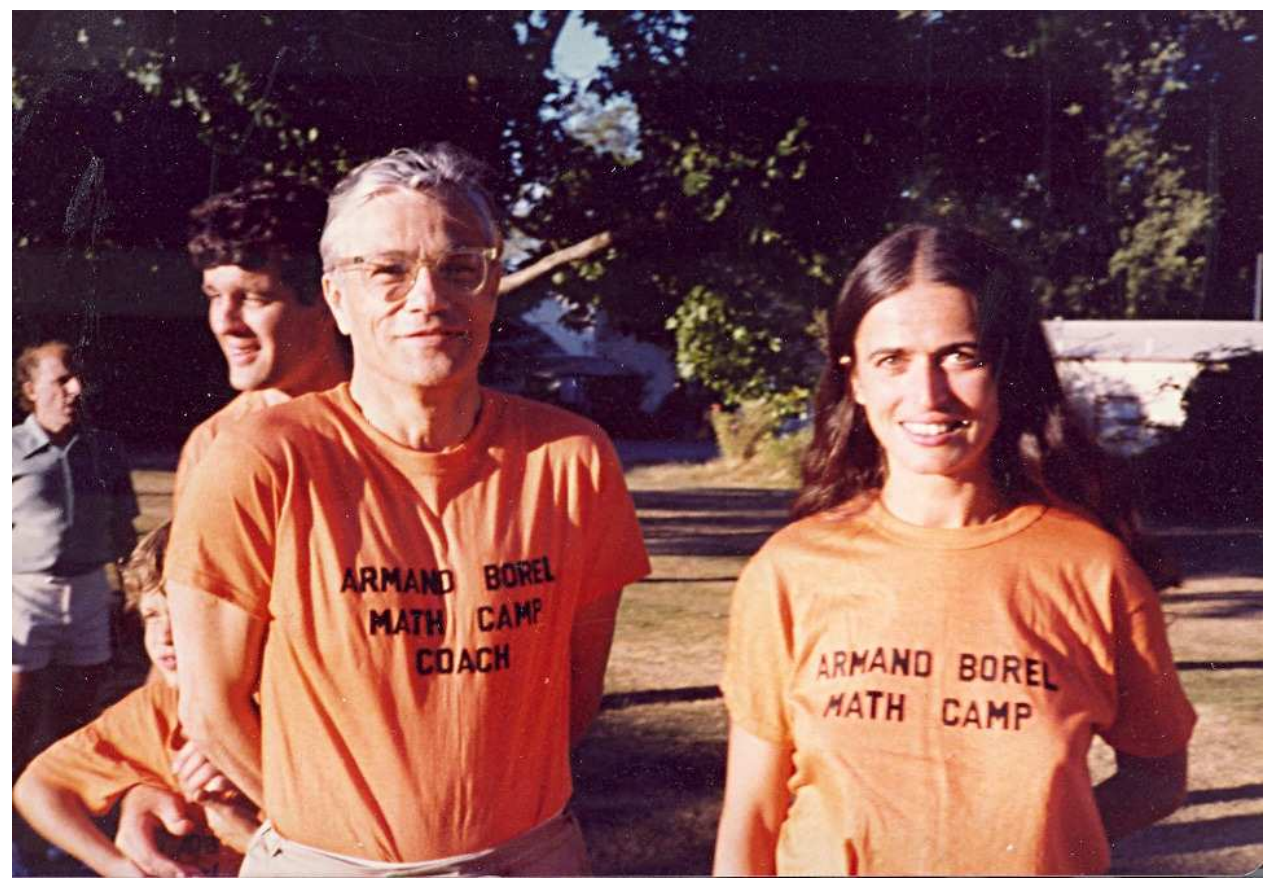

Armand and Marie-France Vigneras at Corvallis

(in the background Roger Howe and Pierre Cartier)

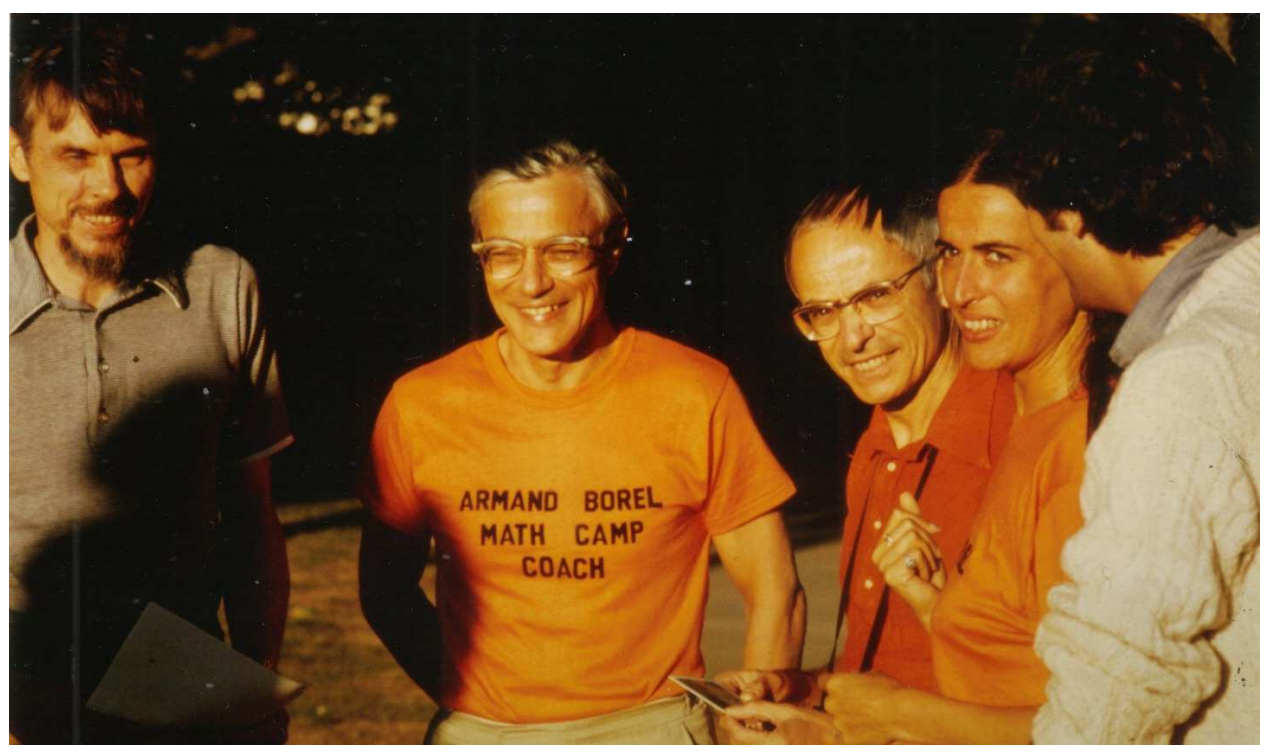

John Tate, Armand, Jean-Pierre Serre, Marie-France, Ken Ribet at Corvallis (photos on this page by Lynn Howe) 


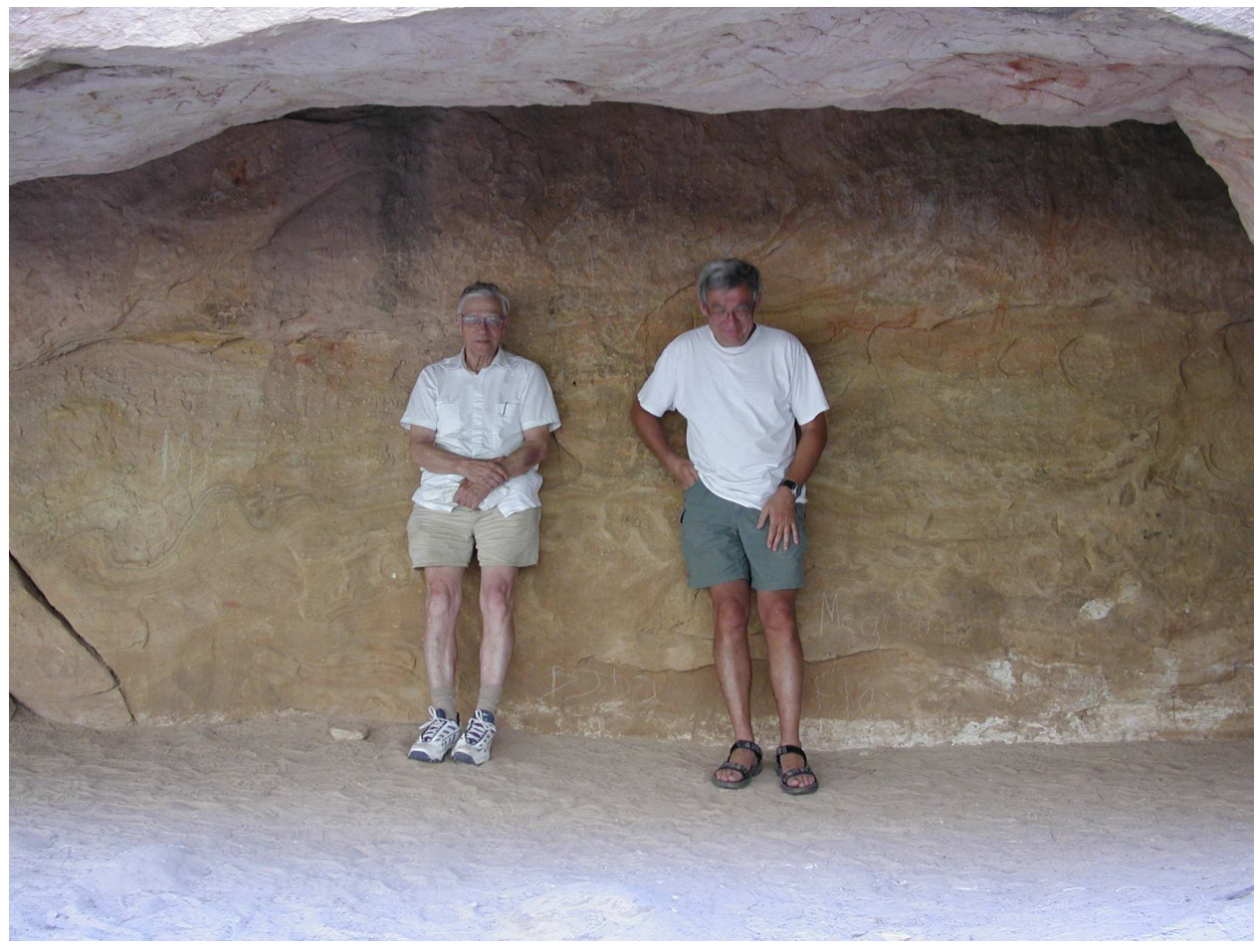

Armand and Dragan Milicic inside the Hole-in-the-Wall, Utah

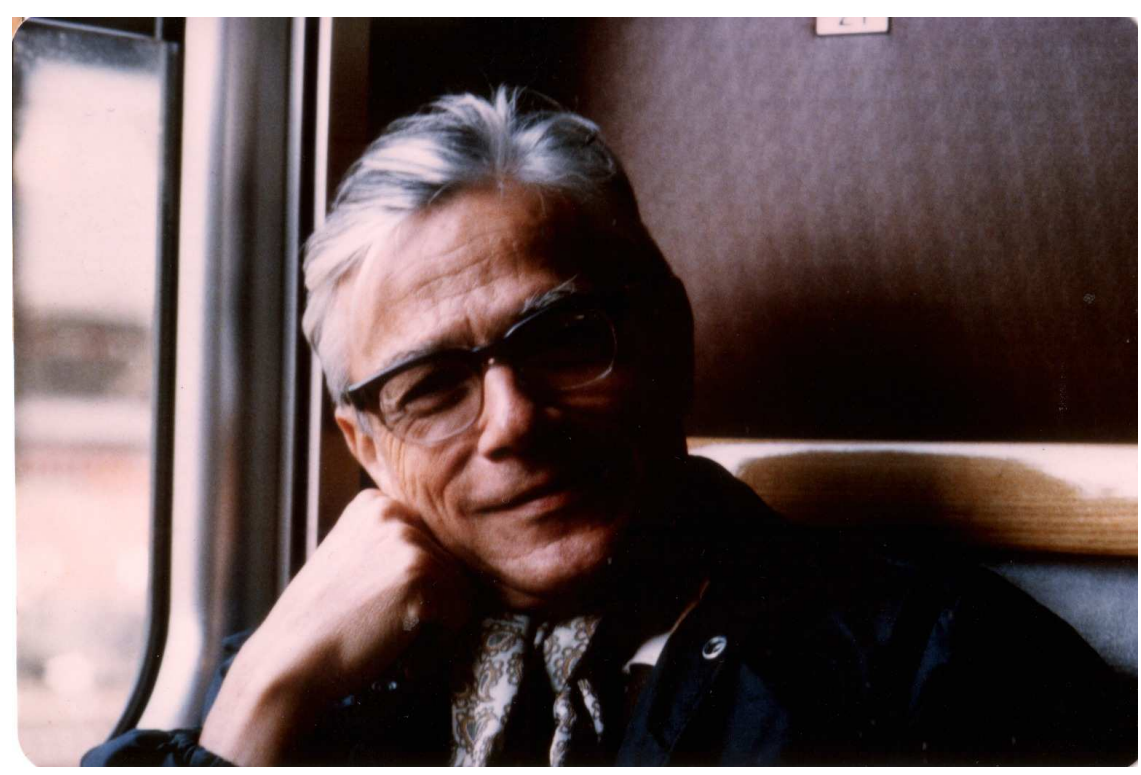

Armand, tired and relaxed, on the train back to Zürich after a hard day of clambering around on Swiss peaks 